\title{
Association of practice size and pay-for-performance incentives with the quality of diabetes management in primary care
}

\author{
Eszter P. Vamos MD PhD, Utz J. Pape PhD, Alex Bottle MSc PhD, Fiona Louise Hamilton MBBS MSc, \\ Vasa Curcin MSc PhD, Anthea Ng BSc, Mariam Molokhia MBBS PhD, Josip Car MD PhD, \\ Azeem Majeed MBBS MD, Christopher Millett PhD
}

\begin{abstract}
Background: Not enough is known about the association between practice size and clinical outcomes in primary care. We examined this association between 1997 and 2005, in addition to the impact of the Quality and Outcomes Framework, a pay-for-performance incentive scheme introduced in the United Kingdom in 2004, on diabetes management.
\end{abstract}

Methods: We conducted a retrospective opencohort study using data from the General Practice Research Database. We enrolled 422 general practices providing care for 154945 patients with diabetes. Our primary outcome measures were the achievement of national treatment targets for blood pressure, glycated hemoglobin $\left(\mathrm{HbA}_{1 \mathrm{c}}\right)$ levels and total cholesterol.

Results: We saw improvements in the recording of process of care measures, prescribing and achieving intermediate outcomes in all practice sizes during the study period. We saw

$\mathrm{T}$ here is a well-established body of literature showing positive associations between volume of patients and clinical outcomes in health care, which has been documented by a systematic review. ${ }^{1}$ However, this association has usually been examined in a limited number of discrete procedures, and most studies have involved hospital-based services rather than primary care settings..$^{2-5}$

Improving our understanding of the association between volume of patients and outcomes in primary care is important for several reasons. First, most contacts with health systems occur in primary care settings, and optimizing the delivery of these services has the potential to improve the health of the population. ${ }^{6}$ Second, over the past decade, primary care has assumed greater responsibility for managing the growing burden of chronic disease. ${ }^{7.8}$ Larger providers may be better resourced, through the employment of additional improvement in reaching national targets after the introduction of the Quality and Outcomes Framework. These improvements significantly exceeded the underlying trends in all practice sizes for achieving targets for cholesterol level and blood pressure, but not for $\mathrm{HbA}_{1 \mathrm{c}}$ level. In 1997 and 2005, there were no significant differences between the smallest and largest practices in achieving targets for blood pressure (1997 odds ratio [OR] 0.98, $95 \%$ confidence interval $[\mathrm{Cl}] 0.82$ to $1.16 ; 2005$ OR $0.92,95 \% \mathrm{Cl} 0.80$ to 1.06 in 2005), cholesterol level (1997 OR 0.94, 95\% Cl 0.76 to 1.16 ; 2005 OR $1.1,95 \% \mathrm{Cl} 0.97$ to 1.40$)$ and glycated hemoglobin level (1997 OR 0.79, 95\% Cl 0.55 to $1.14 ; 2005$ OR $1.05,95 \% \mathrm{Cl} 0.93$ to 1.19 ).

Interpretation: We found no evidence that size of practice is associated with the quality of diabetes management in primary care. Pay-forperformance programs appear to benefit both large and small practices to a similar extent.

support staff and greater use of information technology, to deliver the systematic, structured care necessary for the effective management of chronic disease. ${ }^{6.9}$ Third, larger providers may have been more responsive to nonfinancial and financial incentives, including pay for performance, implemented by payers aimed at improving the quality of care. ${ }^{7,10}$ Fourth, in many countries, primary care is based around a predominance of small practices. $^{6,11,12}$ In 2006, 53\% of practices in England and Wales had three or fewer family physicians. ${ }^{11}$ In the same year in the United States, $30.3 \%$ of family physicians were in solo practice; $9.4 \%$ were in two-physician practices. ${ }^{12}$

Despite the limited data available, concerns have been raised about the standards of care delivered by smaller family practices. ${ }^{13}$ In the United Kingdom and Canada, this has resulted in an explicit policy objective of encouraging smaller practices to amalgamate. ${ }^{13,14}$
Competing interests:

Eszter Vamos, Fiona

Hamilton and Christopher

Millett have received grant funding from the National Institutes of Health

Research (NIHR). Mariam Molokhia has received

grant funding and reimbursement for travel expenses from the Serious Adverse Events

Consortium; she has received funding from AstraZeneca for drug safety studies; she was supported

by an NIHR postdoctoral award during the study; she has received grants from the European Commission's Seventh Framework

Programme; and she has received payment for lectures from the University of Michigan. Azeem

Majeed has received a grant from the UK Department of Health. Alex Bottle has received grant funding from Dr. Foster Intelligence and the National Insitute for Healthcare Research. No other competing interests were declared.

This article has been peer reviewed.

Correspondence to: Dr. Eszter Panna Vamos, e.vamos@imperial.ac.uk

CMAJ 2011. DOI:10.1503 /cmaj.101187 
Our study examines the associations between the size of practice and the quality of diabetes management in UK primary care settings between 1997 and 2005. We tested the hypotheses that patients attending larger family practices receive better care for diabetes and that the quality gap between larger and smaller practices has increased over the past decade. We also hypothesized that larger practices derived more benefit from the Quality and Outcomes Framework, a major pay-for-performance program in primary care introduced in 2004.

\section{Methods}

The General Practice Research Database holds anonymized, longitudinal records of primary care for about $5 \%$ of the people registered with a general practice and is representative of the general UK population. ${ }^{15}$ Participating practices follow an agreed-upon protocol for the collection of demographic and clinical data and submit anonymized records to the database regularly. ${ }^{15}$ The accuracy and completeness of the data have been documented previously, and the database is used extensively for health service and epidemiological research. ${ }^{15-18}$

We obtained an extract from the database containing the medical records of all adult patients $(\geq 18 \mathrm{yr}$ ) with diabetes who were registered with participating practices between 1997 and 2005. For some practices, data were only available for a shorter period or for several shorter intervals during the study period. Patients with diabetes were identified using both diagnostic (C10) and management (66A) Read and Oxford Medical Information Systems codes for diabetes mellitus. ${ }^{19}$

\section{Study variables}

Our primary outcomes were the achievement of national targets for glycated hemoglobin $\left(\mathrm{HbA}_{1 \mathrm{c}}\right)$ level $(\leq 7.0 \%)$, blood pressure $(<140 / 80 \mathrm{~mm}$ $\mathrm{Hg})$ and total cholesterol $(\leq 5 \mathrm{mmol} / \mathrm{L}){ }^{20,21} \mathrm{We}$ used mean annual values where patients had more than one measurement in a year. Practice size was defined as the total number of patients registered in each practice and was assigned to quintiles ( 1 being the smallest and 5 being the largest) (Table 1).

Secondary outcomes included indicators of processes of care (whether blood pressure, cholesterol and $\mathrm{HbA}_{\mathrm{lc}}$ were measured) and prescribing of oral hypoglycaemic, antihypertensive and lipid-lowering medications. Our analyses were adjusted for age, sex, socioeconomic status, duration of diabetes, body mass index and number of comorbid conditions (hypertension, atrial fib- rillation, stroke, heart failure, coronary artery disease, asthma, depression, osteoporosis and chronic obstructive pulmonary disease [COPD]). Based on the postal codes of the general practices involved, socioeconomic status was assigned to each patient using the Index of Multiple Deprivation 2004, the most commonly used method of measuring the socioeconomic status of a neighbourhood in the UK. ${ }^{22}$

\section{Statistical analysis}

The data have a two-level structure as patients are "clustered" within practices. Patient characteristics, process of care and prescribing are described as frequencies or mean values by practice size. Target achievement is described as a mean percentage. Differences between quintiles were compared using Pearson's $\chi^{2}$ test for categorical variables and analysis of variance for normally distributed variables.

We used interrupted time series regression analysis with random effects to assess the impact of pay for performance on the achievement of national targets for blood pressure, $\mathrm{HbA}_{1 \mathrm{c}}$ and cholesterol. Our model estimated three main parameters: the baseline trend in target achievement before the introduction of pay for performance (1997-2003), the immediate effect of the introduction of pay for performance (2004) and the change in slope from before to after the introduction of pay for performance (2004-2005). We used a robust estimator for the standard error to control for the clustering of patients within practices. For the achievement of targets for $\mathrm{HbA}_{\mathrm{lc}}$, only data from 2000-2003 were used to examine the baseline trend, as this was the period when a linear trend was seen.

We also examined differences in the achievement of targets between different quintiles for each year between 1997 and 2005. We used generalized estimating equations adjusting for the clustering of patients within practices (i.e., at the practice level). Unlike standard logistic regression, generalized estimating equations allow for dependence within clusters; patients receiving treatment from the same family practice are expected to have more similar outcomes than patients receiving treatment from different practices. All covariates were entered in both sets of models with none removed. A two-sided $p$ value of less than 0.05 was considered statistically significant.

\section{Results}

We identified 154945 adult patients with diabetes who were registered with 422 participating practices during the overall study period. The number of people with diabetes increased from 


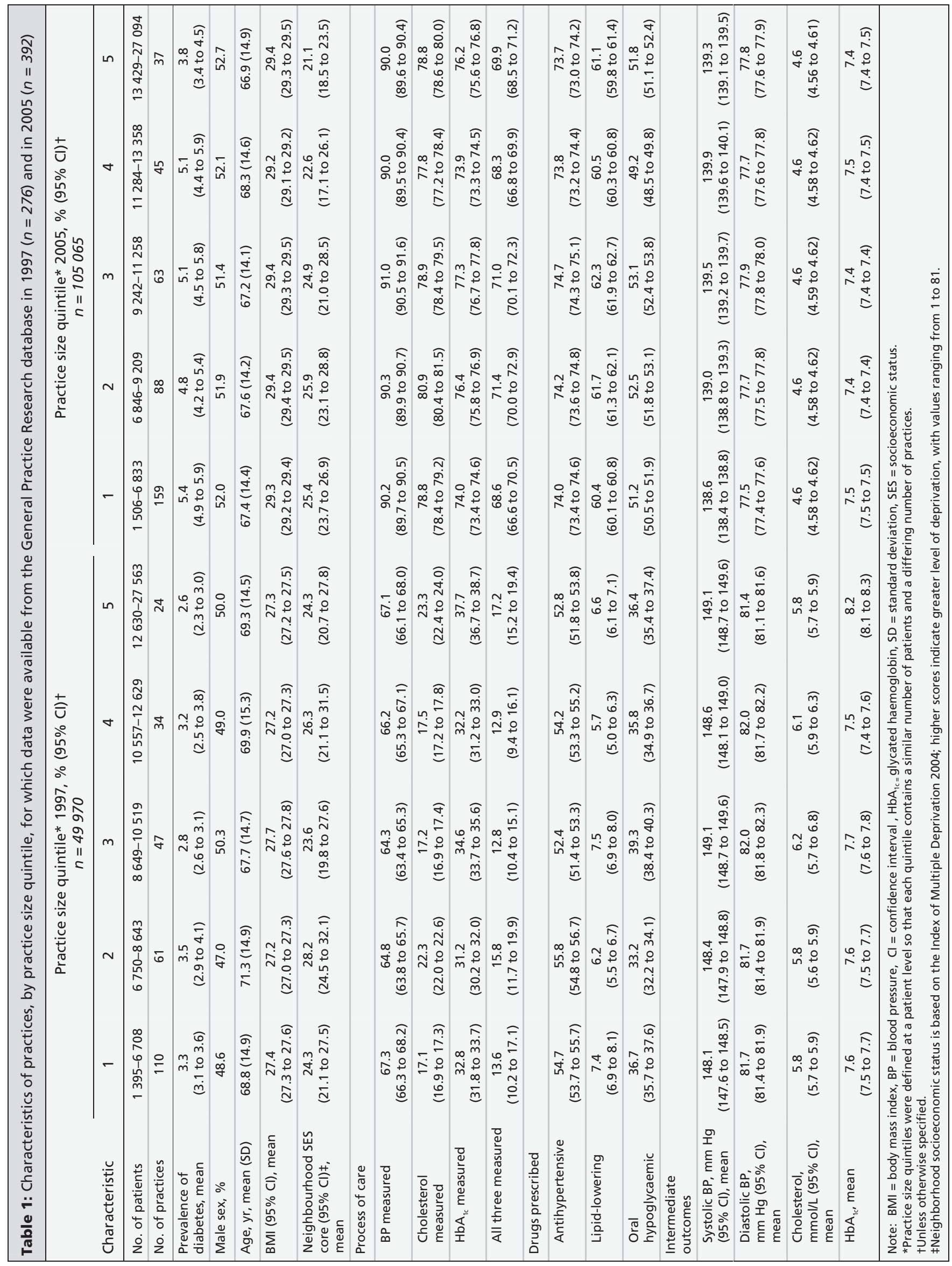


49970 in 1997 to 105065 in 2005 . There were two notable differences in patient characteristics by practice size. The mean prevalence of diabetes was higher in smaller practices in 1997, and this difference further increased by 2005 (Table 1). Furthermore, smaller practices had a higher mean deprivation score (i.e., they were located in more socioeconomically deprived areas) than larger practices in 2005, but not in 1997.

\section{Process of care and prescribing}

There were large improvements in the recording of process measures and the prescription of medications for secondary prevention from 1997 to 2005 (Table 1). However, practice size did not influence processes of care or prescribing within either year.

\section{Achievement of targets}

\section{Blood pressure}

The proportion of patients whose blood pressure met the national target increased in all size groups between 1997 and 2005 (Figure 1, Appendices 1 and 2, available at www.cmaj.ca /lookup/suppl/doi:10.1503/cmaj.101187/-/DC1).

We assessed the effect of pay for performance on the underlying trends in target achievement using interrupted time series analysis (Table 2, Appendix 3, available at www.cmaj.ca/lookup /suppl/doi:10.1503/cmaj.101187/-/DC1). Our model showed that target achievement increased annually by 2.2 percentage points before the introduction of pay for performance, with no difference in improvement between quintiles.

In the year in which pay for performance was introduced, we saw an immediate additional improvement in target achievement of 2.2 percentage points on the top of the pre-existing trend, i.e., an increase of 4.4 percentage points from the previous year. The size of this improvement was significantly lower in the second quintile than in the first quintile (i.e., among the smallest practices) (Table 2).

In the year after pay for performance was introduced, we saw an additional increase of 1.6 percentage points, translating to an accelerated improvement of 3.8 percentage points compared with the 2.2 percentage points per year before the scheme's introduction, with no significant differences in improvement between quintiles.

We used generalized estimating equations to examine the differences in target achievement between quintiles for each year from 1997 to 2005. After adjusting for covariates, there were no statistically significant variations in achieving the national target for blood pressure between the smallest and largest practices in any year during this period (Figure 1, Appendices 1 and 2).

\section{Cholesterol}

The proportion of patients whose total cholesterol levels met the national target improved in all size groups during the study period (Figure 1, Appendices 1 and 3). Before pay for performance was introduced, there was an annual improvement in target achievement of 4.9 percentage points (Table 2). This improvement did not significantly differ between quintiles.

In the year in which pay for performance was introduced, we saw no immediate significant improvement in target achievement.

In the year after pay for performance was introduced, target achievement significantly improved by an additional 2.5 percentage points, for an increase of 7.4 percentage points in comparison with 4.9 percentage points per year before the scheme's introduction. The size of this improvement did not differ between quintiles.

Using generalized estimating equations, we saw that target achievement was lower in the larger practices than in the smallest practices in 1998, but there were no statistically significant variations in performance between small and large practices for other years during the study period (Figure 1, Appendices 1 and 2).

$\mathrm{HbA}_{1 c}$

The proportion of patients meeting the target for $\mathrm{HbA}_{\mathrm{lc}}$ level increased in all quintiles during the study period, but at a lower rate than those seen for blood pressure and total cholesterol (Figure 1).

Before the introduction of pay for performance, target achievement increased annually by 2.0 percentage points (Table 2). Interrupted time series analysis suggests that in the year in which pay for performance was introduced, there was no significant additional improvement in any of the quintiles. In the year after the introduction of pay for performance, target achievement declined by 0.2 percentage points in comparison with the rate before the scheme was introduced.

In 1997, the proportion of patients achieving the target $\mathrm{HbA}_{1 \mathrm{c}}$ level was considerably lower among patients who received treatment from the largest practices $(30.7 \%)$ than among those registered with smaller practices $(40.7 \%)\left(\chi^{2}\right.$ test, $p<$ $0.001)$, but these differences were not significant after adjusting for covariates in generalized estimating equations (Figure 1). In 1999 and 2000, the largest practices had significantly lower target achievement than the smallest practices, but there was no difference in performance in other years.

\section{Interpretation}

During the last decade, there has been substantial improvement in the management of diabetes in 
the $\mathrm{UK}$ in response to a wide range of initiatives and considerable investment in health services. Despite the paucity of information on the association between patient volume and outcome in diabetes care in family practice settings in the UK, there has been much debate about the ability of smaller practices to respond to the incentives offered, to extend the range of preventive services and to deliver comprehensive care for chronic diseases. ${ }^{13}$ Our results show modest absolute differences in the quality of diabetes care between small and large practices in 1997, with these differences narrowing as the study progressed.

The introduction of the Quality and Outcomes

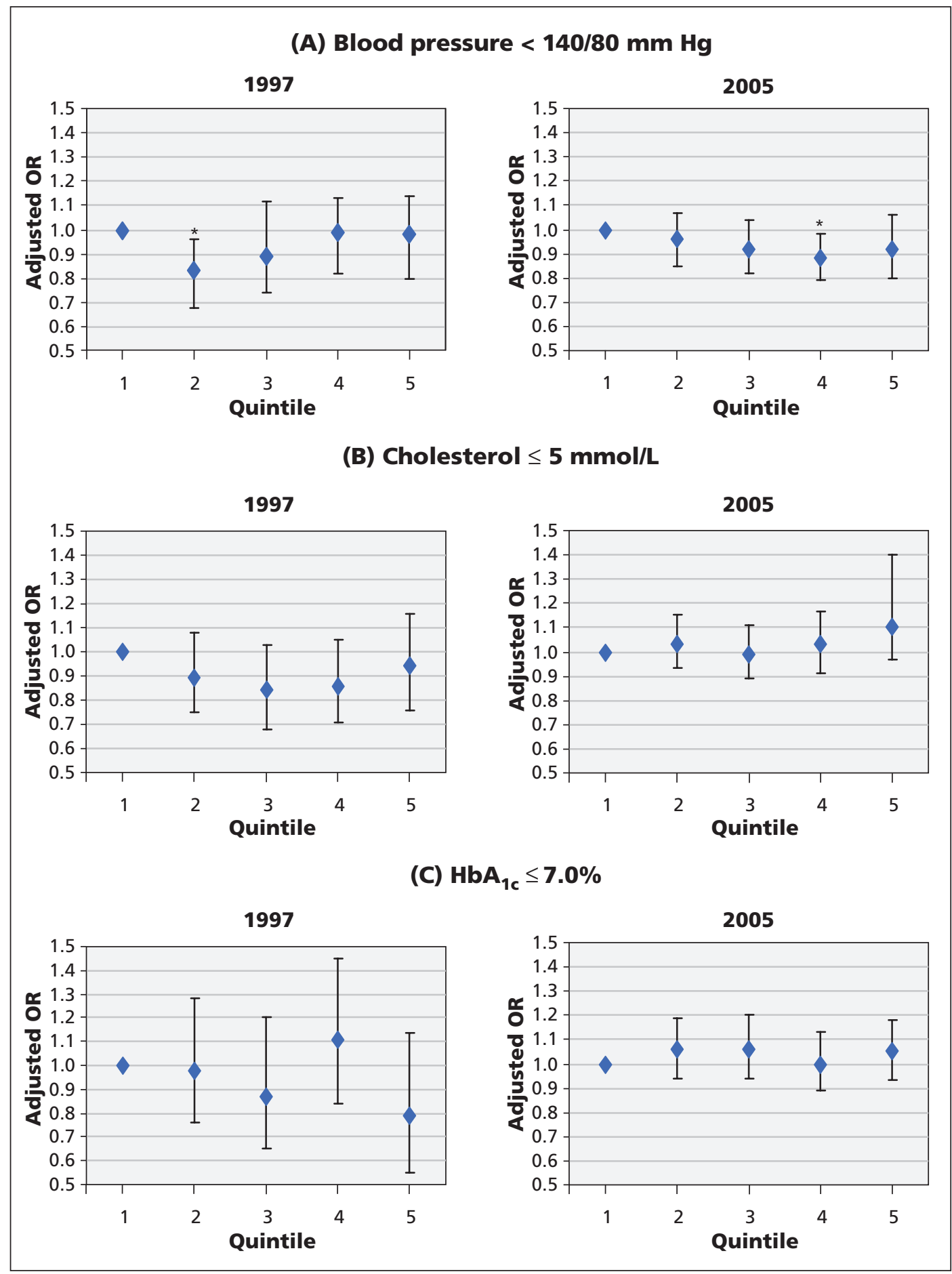

Figure 1: Adjusted generalized estimating equations for the achievement of national targets for blood pressure (A), cholesterol (B) and glycated hemoglobin (C) by practice size (quintile) in 1997 and 2005. Models were adjusted for age, sex, duration of diabetes, body mass index, socioeconomic status and number of comorbid conditions. Error bars indicate $95 \%$ confidence intervals. $\mathrm{HbA}_{\mathrm{cc}}=$ glycated hemoglobin, $\mathrm{OR}=$ odds ratio. ${ }^{*} p<0.05$. 
Framework was associated with accelerated improvement in controlling blood pressure and total cholesterol levels that was higher than predicted by the underlying trends before the scheme was introduced, with no differences between the smallest and largest practices. There was already evidence of rapid improvements in the quality of clinical care before pay for performance. Our study builds on the literature by isolating the impact of this pay-for-performance scheme from existing trends in practices of different sizes. ${ }^{23} \mathrm{By}$ 2005, we found improved attainment of targets for cholesterol level and blood pressure that exceeded the underlying trends in all practice sizes. Such an improvement was not seen for the achievement of the target for $\mathrm{HbA}_{\mathrm{lc}}$ level, which is consistent with the results of other studies. ${ }^{23,24}$ Because the control of blood glucose levels requires greater involvement of the patient with his or her care, as well as the cooperation of family practitioners and staff, it might be expected to be more sensitive to the organizational characteristics of practice (e.g., size) than the control of blood pressure or cholesterol.

\section{Comparison with other studies}

Previous studies examining the associations between volume of patients and health outcomes in primary care have produced conflicting results. Some studies showed that the size of a practice had no impact on diabetes control, although smaller

Table 2: Parameter estimates from the interrupted time series analyses* looking at changes in the achievement of established treatment targets between 1997 and 2005 by practice size quintile

\begin{tabular}{|c|c|c|c|}
\hline \multirow[b]{2}{*}{ Variable } & \multicolumn{3}{|c|}{$\begin{array}{l}\text { Proportion of patients meeting the target relative to the } \\
\text { reference, } \%+(95 \% \mathrm{Cl})\end{array}$} \\
\hline & $\mathrm{BP}<140 / 80 \mathrm{~mm} \mathrm{Hg}$ & $\begin{array}{l}\text { Cholesterol } \\
\leq 5 \mathrm{mmol} / \mathrm{L}\end{array}$ & $\mathrm{HbA}_{1 \mathrm{c}} \leq 7.0 \%$ \\
\hline $\begin{array}{l}\text { Baseline proportion of patients } \\
\text { meeting treatment target in } 1997\end{array}$ & $24.0(21.0$ to 26.0$) \ddagger$ & 19.2 (16.4 to 22.0$) \ddagger$ & 35.3 (31.0 to 39.7$) \neq$ \\
\hline $\begin{array}{l}\text { Annual change before } \\
\text { introduction of pay for } \\
\text { performance, percentage points }\end{array}$ & $2.2(1.9$ to 2.6$) \ddagger$ & 4.9 (4.3 to 5.3$) \ddagger$ & 2.0 (1.3 to 2.7$) \ddagger$ \\
\hline $1 \S$ & 1.00 & 1.00 & 1.00 \\
\hline 2 & $-0.1(-0.7$ to 0.4$)$ & 0.09 (-0.6 to 0.7$)$ & $0.3(-0.8$ to 1.4$)$ \\
\hline 3 & 0.3 (-0.2 to 0.8$)$ & $0.5(-0.2$ to 1.2$)$ & $0.2(-1.2$ to 1.7$)$ \\
\hline 4 & $-0.3(-0.8$ to 0.2$)$ & $0.6(-0.1$ to 1.4$)$ & $0.04(-1.2$ to 1.3$)$ \\
\hline 5 & $-0.2(-0.7$ to 0.4$)$ & $0.8(-0.1$ to 1.8$)$ & $1.3(-0.03$ to 2.6$)$ \\
\hline $\begin{array}{l}\text { Change in the year pay for } \\
\text { performance was introduced, } \\
\text { percentage points }\end{array}$ & $2.2(0.2$ to 4.2$) \ddagger$ & $1.7(-0.3$ to 3.7$)$ & 0.8 (-1.8 to 3.5$)$ \\
\hline 1 & 1.00 & 1.00 & 1.00 \\
\hline 2 & $-2.7(-5.3$ to -0.01$)$ গ & $1.0(-1.8$ to 3.9$)$ & $-3.2(-7.2$ to 0.8$)$ \\
\hline 3 & $-1.2(-4.3$ to 2.0$)$ & $-1.3(-4.3$ to 1.8$)$ & $-1.7(-5.6$ to 2.1$)$ \\
\hline 4 & $-1.5(-4.0$ to 1.0$)$ & 1.2 (-1.6 to 4.1$)$ & $-3.7(-7.7$ to 0.3$)$ \\
\hline 5 & $-0.5(-3.3$ to 2.3$)$ & $1.0(-1.9$ to 4.0$)$ & $0.09(-4.2$ to 4.4$)$ \\
\hline $\begin{array}{l}\text { Annual change after pay for } \\
\text { performance was introduced, } \\
\text { percentage points }\end{array}$ & $1.6(0.5 \text { to } 2.7)^{* *}$ & 2.5 (1.1 to 3.9$) \ddagger$ & $-2.2(-4.0$ to -0.4$)$ ๆ \\
\hline 1 & 1.00 & 1.00 & 1.00 \\
\hline 2 & $1.0(-0.7$ to 2.8$)$ & $-0.2(-2.1$ to 1.6$)$ & $2.5(-0.2$ to 5.0$)$ \\
\hline 3 & $-0.7(-2.4$ to 1.0$)$ & $-0.02(-2.1$ to 2.1$)$ & $2.5(-0.2$ to 5.2$)$ \\
\hline 4 & $0.5(-1.1$ to 2.1$)$ & $-1.9(-4.1$ to 0.3$)$ & $2.9(-0.07$ to 5.9$)$ \\
\hline 5 & $-0.04(-2.0$ to 1.9$)$ & $-1.1(-3.4$ to 1.1$)$ & $0.6(-2.7$ to 4.0$)$ \\
\hline \multicolumn{4}{|c|}{$\begin{array}{l}\text { Note: } \mathrm{BP}=\text { blood pressure, } \mathrm{Cl}=\text { confidence interval, } \mathrm{HbA}_{1 \mathrm{C}}=\text { glycated hemoglobin. } \\
* \text { Interrupted time series analyses models were adjusted for age, sex, duration of diabetes, body mass index, deprivation and } \\
\text { number of comorbid conditions. } \\
\text { tUnless otherwise specified. } \\
\neq p<0.05 \text {. } \\
\$ 1=\text { smallest practices, } 5=\text { largest practices. } \\
\uparrow p<0.01 . \\
\star \star p<0.001 .\end{array}$} \\
\hline
\end{tabular}


practices were more accessible and had better interpersonal care, provided better continuity of care and achieved higher levels of satisfaction among patients compared with larger practices. ${ }^{2-4,2526}$ Other studies reported superior diabetes control in larger practices. Our results correspond with other studies that suggest high-level recording of process measures but persisting suboptimal achievement of established intermediate outcome targets. ${ }^{5,27}$

\section{Strengths and limitations}

Our study involved a large, representative sample of people with diabetes in the UK. Almost the entire population of the UK is registered with a family practitioner, and people can only be registered with one practice at a time. We were thus able to accurately calculate the prevalence of disease prevalence and rates of treatment. ${ }^{28}$

Before the introduction of pay for performance, coding may have been less accurate owing to the lack of financial incentive. Payments to family practices under the current contract are weighted by the prevalence of diabetes, hence there is a financial incentive to identify and report all cases of the disease. ${ }^{29}$

Because of the lack of data on the races and ethnicities of patients, we could not determine whether these factors might influence our outcome measures. Were were also unable to distinguish between type 1 and type 2 diabetes.

Single-handed practices are under-represented in the General Practice Research Database, meaning that we may not have captured the full diversity of small practices.

Because most of the patients involved in this study had one recorded measurement for cholesterol and $\mathrm{HbA}_{1 \mathrm{c}}$, we used mean annual values where patients had more than one measurement annually.

The basis for our analyses was the assumptions that the introduction of pay for performance was responsible for the differences seen between trends before and after the start of the program. We analyzed trends in target achievement over seven time points before the introduction of the framework. However, the estimations for the achievement of $\mathrm{HbA}_{\mathrm{lc}}$ targets may be less robust than those for blood pressure and cholesterol targets; the estimations for $\mathrm{HbA}_{\mathrm{lc}}$ were based on trends over a fouryear period from 2000 to 2003 , which is when a linear trend was seen. Our approach is superior to previous research designs that predicted performance based on two time points before the introduction of pay for performance. ${ }^{5,30}$ Furthermore, our analyses have been adjusted for several characteristics that might have varied during the study period. ${ }^{31}$ For example, smaller practices were more likely to be located in socioeconomically deprived areas in 2005, but not in 1997. One possible explanation is that smaller practices in more affluent areas might have been more likely to amalgamate into multipartner practices compared with smaller practices in more deprived areas. ${ }^{11}$

We did not have information on the number of family practitioners employed and infrastructure support provided by practices. The framework, however, does not consider the number of full-time equivalent physicians employed in a practice; rather, it looks at the quality of care provided by the practice team as a whole..$^{29}$

\section{Conclusion}

We found no evidence that smaller practices provided lower quality of care for diabetes or benefited less from pay for performance than larger practices in UK primary care settings. Our data support the view that different types of practices might have different strengths, and no single type of practice has a monopoly on high-quality care. ${ }^{3}$ Our findings are of particular importance at a time when health care managers increasingly promote the consolidation of practices into larger units as a means of improving quality of care. Decisions about the consolidation of primary care-for example, through the development of polyclinics-should continue to be based on the performance of health systems at a local level to address deficiencies in access to primary care and the quality of local health services.

\section{References}

1. Halm EA, Lee C, Chassin MR. Is volume related to outcome in health care? A systematic review and methodologic critique of the literature. Ann Intern Med 2002;137:511-20.

2. Campbell JL, Ramsay J, Green J. Practice size: impact on consultation length, workload, and patient assessment of care. $\mathrm{Br} \mathrm{J}$ Gen Pract 2001;51:644-50.

3. Campbell SM, Hann M, Hacker J, et al. Identifying predictors of high quality care in English general practice: observational study. BMJ 2001;323:784-7.

4. Millett C, Car J, Eldred D, et al. Diabetes prevalence, process of care and outcomes in relation to practice size, caseload and deprivation: national cross-sectional study in primary care. $J R$ Soc Med 2007; 100:275-83.

5. Tahrani AA, McCarthy M, Godson J, et al. Impact of practice size on delivery of diabetes care before and after the Quality and Outcomes Framework implementation. Br J Gen Pract 2008;58:576-9.

6. World Health Organization. The WHO Health Report 2008: primary health care now more than ever. Geneva: The Organization; 2008. Available:www.who.int/whr/2008/whr08_en.pdf (accessed 2010 Dec. 18).

7. Department of Health. The new NHS: modern, dependable. London (UK): The Department; 1997. Available: www.dh.gov.uk /en/Publicationsandstatistics/Publications/PublicationsPolicyAnd Guidance/DH_4008869 (accessed 2010 Dec. 18).

8. Department of Health. Our health, our care, our say: a new direction for community services. London (UK): The Department; 2006. Available: www.dh.gov.uk/en/Publicationsandstatistics /Publications/PublicationsPolicyAndGuidance/DH_4127453 (accessed 2010 Dec. 18).

9. Casalino LP. Which type of medical group provides higherquality care? Ann Intern Med 2006;145:860-1.

10. Department of Health. The NHS Plan: a plan for investment, a plan for reform. London (UK): The Department; 2000. Available: www .dh.gov.uk/en/Publicationsandstatistics/Publications/Publications PolicyAndGuidance/DH_4002960 (accessed 2010 Dec. 18).

11. Atenstaedt R. Single-handed or group practice, quality of care and patient satisfaction. Br J Gen Pract 2006;56:301. 
12. 2007 Survey of primary care physicians. Irving (TX): Merritt Hawkins \& Associates; 2007. Available: www.merritthawkins .com/pdf/2007_survey_primarycare.pdf (accessed 2010 Dec. 18).

13. Majeed A. The future of singlehanded general practices. BMJ 2005;330:1460-1.

14. Iglehart JK. Revisiting the Canadian health care system. $N$ Engl J Med 2000;342:2007-12.

15. Hollowell J. The General Practice Research Database: quality of morbidity data. Popul Trends 1997; Spring:36-40.

16. Millett C, Bottle A, Ng A, et al. Pay for performance and the quality of diabetes management in individuals with and without comorbid medical conditions. J R Soc Med 2009;102:369-77.

17. The General Practice Research Database. London (UK): The Database; 2011. Available: www.gprd.com/home (accessed 2010 Dec. 18).

18. Lawrenson R, Williams T, Farmer R. Clinical information for research; the use of general practice databases. J Public Health Med 1999;21:299-304

19. Gray J, Orr D, Majeed A. Use of Read codes in diabetes management in a south London primary care group: implications for establishing disease registers. BMJ 2003;326:1130.

20. National Institute for Health and Clinical Excellence. Type 2 diabetes - management of blood pressure and blood lipids London (UK): The Institute; 2002. Available: www.nice.org.uk /Guidance/H (accessed 2010 Dec. 18).

21. America Diabetes Association. Standards of medical care in diabetes - 2007. Diabetes Care 2007;30(Suppl 1):S4-41.

22. Index of multiple deprivation. London (UK): Department of Communities and Local Government; 2004. Available: www .communities.gov.uk/publications/communities/englishindices (accessed 2011 July 20)

23. Campbell SM, Roland MO, Middleton E, et al. Improvements in quality of clinical care in English general practice 1998-2003: longitudinal observational study. BMJ 2005;331:1121.

24. Shojania KG, Ranji SR, McDonald KM, et al. Effects of quality improvement strategies for type 2 diabetes on glycemic control: a meta-regression analysis. JAMA 2006;296:427-40.

25. Schaars CF, Denig P, Kasje WN, et al. Physician, organizational, and patient factors associated with suboptimal blood pressure management in type 2 diabetic patients in primary care. Diabetes Care 2004;27:123-8.

26. Khunti K, Ganguli S, Baker R, et al. Features of primary care associated with variations in process and outcome of care of people with diabetes. Br J Gen Pract 2001;51:356-60.

27. Gulliford MC, Ashworth M, Robotham D, et al. Achievement of metabolic targets for diabetes by English primary care practices under a new system of incentives. Diabet Med 2007;24:505-11.

28. Gnani S, Majeed A. A user's guide to data collected in primary care in England. Cambridge (UK): Eastern Region Public Health Observatory; 2006. Available: www.erpho.org.uk/Download/Public /12899/1/erpho\%20Primary\%20Care.pdf (accessed 2010 Dec. 18).

29. Roland M. Linking physicians' pay to the quality of care - a major experiment in the United Kingdom. N Engl J Med 2004; 351:1448-54.

30. Campbell S, Reeves D, Kontopantelis E, et al. Quality of primary care in England with the introduction of pay for performance. N Engl J Med 2007;357:181-90.

31. Ashworth M, Seed P, Armstrong D, et al. The relationship between social deprivation and the quality of primary care: a national survey using indicators from the UK Quality and Outcomes Framework. Br J Gen Pract 2007;57:441-8.
Affiliations: From the Department of Primary Care \& Public Health (Vamos, Pape, Bottle, Hamilton, Ng, Car, Majeed, Millett), Imperial College, London, UK; the Department of Computing (Curcin), Imperial College, London, UK; and the Department of Primary Care \& Public Health Sciences (Molokhia), King's College London, UK

Contributors: Eszter Vamos, Alex Bottle and Utz Pape contributed to the analysis of the data, interpreted the results and drafted the manuscript. Alex Bottle and Utz Pape contributed to the analysis of the data, interpreted the results and revised the manuscript. Fiona Hamilton interpreted the results and revised the manuscript. Vasa Curcin, Anthea Ng and Mariam Molokhia extracted the data, contributed to the analysis of the data and revised the manuscript. Josip Car, Azeem Majeed and Christopher Millett formulated the original research question. Josip Car revised the manuscript for important intellectual content. Azeem Majeed amd Christopher Millett conceived of the idea for the present analysis, supervised the study, interpreted the results and wrote the manuscript. Azeem Majeed had full access to all the data in the study and takes responsibility for the integrity of the data and the accuracy of the data analysis. All of the authors approved the final version of the manuscript submitted for publication.

Funding: This study represents independent research commissioned by the National Institute for Health Research Service Delivery and Organisation Programme. The views expressed in this publication are those of the authors and not necessarily those of the UK National Health Service, the National Institute for Health Research (NIHR) or the Department of Health. Eszter Vamos is funded by a Marie Curie Fellowship. Alex Bottle is funded by Dr Foster Intelligence. Mariam Molokhia was supported by an NIHR postdoctoral award during the study. Vasa Curcin is funded by the NIHR. Christopher Millett is funded by the Higher Education Funding Council for England and NIHR. Imperial College receives a contribution toward Azeem Majeed's salary from the UK Diabetes Research Network

Acknowledgements: This study is based in part on data from the Full Feature General Practice Research Database, obtained under license from the UK Medicines and Healthcare Products Regulatory Agency. Access to the database was funded through the UK Medical Research Council's license agreement with the Medicines and Healthcare Products Regulatory Agency. The Department of Primary Care and Public Health at Imperial College is grateful for support from the NIHR Biomedical Research Centre Scheme, the National Institute for Health Research Collaboration for Leadership in Applied Health Research and Care Scheme, and the Imperial Centre for Patient Safety and Service Quality. 